\title{
Hypertension: A Review
}

\author{
Midhun Kumar G.H. ${ }^{1}$, Shanmuga Priyan ${ }^{2}$, Arunachalam P. ${ }^{3}$, Elavarasan K. ${ }^{4}$ \\ ${ }^{1}$ Associate Professor, Department of Community Medicine, Meenakshi Medical College Hospital and Research \\ Institute, Enathur, Kanchipuram, Tamilnadu, India, ${ }^{2}$ Associate Professor, Department of Pharmacology, Meenakshi \\ Medical College Hospital and Research Institute, Enathur, Kanchipuram, Tamilnadu, India, ${ }^{3}$ Professor \& HOD, \\ Department of Cardiology, Meenakshi Medical College Hospital and Research Institute, Enathur, Kanchipuram, \\ Tamilnadu, India, ${ }^{4}$ Senior Resident, Department of General Medicine, Meenakshi Medical College Hospital and \\ Research Institute, Enathur, Kanchipuram, Tamilnadu, India
}

\begin{abstract}
Throughout the world, as per research about 1.13 billion people are affected by hypertension. The increase in blood pressure which is unable to be handled at a given situation is known as hypertension. People from middle and low income countries are affected due to the hypertension. This is due to the high expectation in living style, job dissatisfaction, and comparison between persons. This phenomenon is becoming a burden throughout the world and it is affecting the younger generation. This leads to decrease in life expectancy and it is a leading cause of deaths around the world. This paper analyses the various reasons for the hypertension and its causes and the obtained results are summarized.
\end{abstract}

Keywords: Hypertension, risk factor, determinants, occupational stress, DALYs

\section{Introduction}

Elevated blood pressure in medical terms is known as Hypertension. It is a serious condition in which the end organ damage is very obvious. Around the world about 1 in 4 among men and 1 in 5 in women affected by hypertension which amounts to about 1.13 billion. Many of those affected are from middle and low income countries. The prevalence of hypertension in India is found to be about $30.7 \%$, according to a study conducted in India. The men in India are found to be more prone to developing the disease when compared to men. ${ }^{[2]} \mathrm{In}$ Tamil Nadu the prevalence was reported to be $21.4 \%$ and the prevalence was same in both the genders. ${ }^{[3]}$ In a Meta analysis published shows the hypertension to be

\section{Corresponding Author:}

\section{Midhun Kumar G.H.}

Associate Professor, Department of Community

Medicine, Meenakshi Medical College Hospital and

Research Institute, Enathur, Kanchipuram, Tamilnadu, India

e-mail: midhunkumargh@mmchri.ac.in
$27.6 \%$ in rural areas of India. ${ }^{[4]}$ It is also leading cause of mortality and global disability-adjusted life years (DALYs). In 2015 it was observed those 10.7 million deaths and $20.9 \%$ of all DALYS. It was also estimated that the killer disease is becoming more prevalent in children and adolescents. The prevalence is more in low and middle income countries than those in high income countries and it is the same in European countries. ${ }^{[5]}$ It was also estimated that a reduction in the prevalence of hypertension by $17 \%$, which was attributed to reduction in salt intake would prevent 24.3 thousand deaths by the year 2030. It was also suggested that by reducing the deaths by hypertension can reduce the additional cost of hypertension by 6 to 8 folds. ${ }^{[6]}$. Thus, hypertension is a major disease and a leading cause of DALY and deaths around the world.

Though there are many studies on hypertension, there is not much study done in rural population and in our country. This article is a review work done on hypertension, especially in the rural population of our country. Hence this study will provide an insight into the hypertension status in our country and especially in rural population. 


\section{Material and Method}

Data were taken from Google scholar and Pubmed by using terms such hypertension, rural, risk factors from January 2000 to September 2020. Articles which were available as full text and in the English language were selected. All articles related including cross sectional, descriptive, cohort, randomized, non randomized, qualitative and systematic studies were taken. About 30 articles were in total. Based on non availability of full text articles 19 were excluded. So finally 11 were included.

\section{Result}

Socio demographic determinants: In a study conducted among tribal population the prevalence of hypertension was found to be different in different states. It was found to be higher in Orissa (55\%) and lowest in Gujarat with prevalence to be around $11 \%$. Among those diagnosed as hypertensives more than half were taking treatment for the condition. According to the same study, elderly people were more at risk of developing hypertension when compared to the younger population. Abdominal and also general obesity were found to be a major risk factor. Age, literacy obesity and physical activity were found to be statistically significant. ${ }^{[7]}$

In a study conducted among tribal population the prevalence of hypertension was observed to be 27.1 $\%$ among men and $26.4 \%$ among the women. Of those who were found to be hypertensive's only $10 \%$ were previously diagnosed rest were only newly diagnosed rest all were known hypertensive sans more than half (55$68 \%$ ) were taking. In a study conducted among the rural population, it was found that the prevalence increased with age advancement. Hypertension was found to be more prevalent in people of higher socioeconomic strata. It was also reported that a higher socioeconomic group about $15 \%$ - $35 \%$ of the people were having obesity. About $69 \%$ of the men and women have reported low vegetable intake. And about $33 \%$ men had dyslipidemia in higher socioeconomic groups. Where else in the lower socioeconomic group only about $13 \%$ of them were having obesity. And risk factors for developing any non communicable disease was found to be more in south Indians when compared to North Indians. It was reported that dyslipidemia was seen in $21 \%$ of the North Indians when compared to South Indians where the percentage was $33 \%$. It was also reported that only $13 \%$ of the North Indian women had obesity where else $24 \%$ of the South Indian women were suffering from obesity. ${ }^{[8]}$
In one another cross sectional study conducted the prevalence of hypertension was found to be $7.24 \%$. It was reported as age advances the prevalence also increases. Like it was $0.41 \%$ among $19-28$ years whereas, it was $31 \%$ among subjects of around 79 years. Age was also statistically significant with hypertension. Among the genders, women $55.2 \%$ had hypertension, but in men it was only $44.6 \%$ and gender was not statistically significant. About $5.58 \%$ who had hypertension had a normal Body Mass Index. But those with increased BMI had higher prevalence of hypertension. It was found that about $5.31 \%$ were reported to take extra salt and among those, more than half were found to be hypertensives. ${ }^{[9]}$

In a study, conducted among rural population the prevalence of hypertension was found to be $14 \%$. The prevalence was more in age group above 35 years. It was also observed that income had no effect on the disease development. It was also reported that $72 \%$ of the people who were having hypertension. The different education levels showed a difference in hypertension. About $20.7 \%$ of the subjects who had increased level of cholesterol had hypertension. It was also found that cholesterol levels and development of hypertension was found to be statistically significant. ${ }^{[10]}$

Psychosocial determinants: In a study conducted among tribal population the alcohol consumption was associated with disease development. The alcohol and tobacco habits were all statistically significant with the disease development. ${ }^{[7]}$

In a review article it was reported that $40 \%$ of the men and about $4 \%$ of the women had the habit of consuming tobacco. It was observed that people in the lower socioeconomic group had been using tobacco more when compared to those in higher socioeconomic group. ${ }^{[8]}$

In a study conducted among rural population the tobacco intake showed no significance. The alcohol intake had a significant risk of developing the disease. ${ }^{[9]}$ In a review study conducted it was found that occupational stress was linked with hypertension. The various studies taken for explained the relationship between work stress and hypertension. It was also observed that immigrant population had varying hypertension state when compared to the general population. It was concluded that acculturation had an effect on disease development. ${ }^{[11]}$ 
Public health considerations: Most people due to changes in lifestyle are prone to non communicable diseases such as Hypertension. Though it is a well known disease, but still takes light from the people around the world, especially in developing countries like India that too people in rural population are very highly affected.

Government of India has already brought in programs for screening, treatment and management of complications. But not that it has reached the rural population in many areas of the country. So the general public should be made aware of the risk factors, signs and symptoms, the complications and about the dangers of not taking proper treatment. They should also be made aware that hypertension is curable when diagnosed early we can avoid any further complications.

\section{Conclusion}

The major risk factors identified were age, socioeconomic status and habits such as alcohol consumption and smoking. It was also identified that hypertension is more among the rural population and also among migrants as these are the areas where the health care becomes difficult to reach due to environmental factors and various other determinants.

\section{Ethical Clearance: Nil}

Source of Funding: Meenakshi Academy of Higher Education and Research, Chennai, India

\section{Conflict of Interest: Nil}

\section{References}

1. World Health Organisation. Hypertension. 20119 Sept 2019. Last assessed on: October 20, 2020.

2. Ramakrishnan S, Zachariah G, Gupta K, Rao JS, Mohanan PP, Venugopal K, Sateesh S, Sethi R, Jain D, Bardolei N, Mani K. Prevalence of hypertension among Indian adults: Results from the great India blood pressure survey. Indian heart journal. 2019 Jul 1;71(4):309-13.

3. Prasad R. 21.4 p.c. prevalence of hypertension in rural Tamil Nadu: study. 155 June 2016. Last assessed on: October 20, 2020.
4. Anchala R, Kannuri NK, Pant H, Khan H, Franco OH, Di Angelantonio E, Prabhakaran D. Hypertension in India: a systematic review and meta-analysis of prevalence, awareness, and control of hypertension. Journal of hypertension. 2014 Jun;32(6): 1170.

5. Camm AJ, Lucher FS, Maurer G. Epidemiology and global burden of hypertension. 2018 Dec. Last assessed on: October 10, 2020.

6. Nugent RA, Husain MJ, Kostova D, Chaloupka F. Introducing the PLOS special collection of economic cases for NCD prevention and control: A global perspective. Plos one. 2020 Feb 6;15(2):e0228564

7. Laxmaiah A, Meshram II, Arlappa N, Balakrishna N, Rao KM, Reddy CG, Ravindranath M, Kumar S, Kumar H, Brahmam GN. Socio-economic \& demographic determinants of hypertension \& knowledge, practices \& risk behaviour of tribals in India. The Indian journal of medical research. 2015 May;141(5):697.

8. Kinra S, Bowen LJ, Lyngdoh T, Prabhakaran D, Reddy KS, Ramakrishnan L, Gupta R, Bharathi AV, Vaz M, Kurpad AV, Smith GD. Sociodemographic patterning of non-communicable disease risk factors in rural India: a cross sectional study. Bmj. 2010 Sep 27;341:c4974.

9. Todkar SS, Gujarathi VV, Tapare VS. Period prevalence and sociodemographic factors of hypertension in rural Maharashtra: a cross-sectional study. Indian journal of community medicine: official publication of Indian Association of Preventive \& Social Medicine. 2009 Jul;34(3):183.

10. Kishore J, Gupta N, Kohli C, Kumar N. Prevalence of hypertension and determination of its risk factors in rural Delhi. International journal of hypertension. 2016 Apr 3;2016.

11. Kaplan MS, Nunes A. The psychosocial determinants of hypertension. Nutrition, metabolism and cardiovascular diseases. $2003 \mathrm{Feb}$ 1; 13(1):52-9. 